\title{
Portulaca Extract Attenuates Development of Dextran Sulfate Sodium Induced Colitis in Mice through Activation of PPAR $\gamma$
}

\author{
Rui Kong $\mathbb{D}^{1,2}$ Hui Luo, ${ }^{1}$ Nan Wang $\mathbb{D},{ }^{1}$ Jingjing Li $\mathbb{D},{ }^{1}$ Shizan $X u,{ }^{1,3}$ Kan Chen $\mathbb{D},{ }^{1}$ \\ Jiao Feng, ${ }^{1}$ Liwei Wu, ${ }^{1}$ Sainan Li, ${ }^{1}$ Tong Liu, ${ }^{1}$ Xiya Lu, ${ }^{1}$ Yujing Xia ${ }^{D},{ }^{1}$ Yanhong Shi, \\ Yingqun Zhou $\left(\mathbb{D},{ }^{1}\right.$ Weigang He $\mathbb{D}^{4},{ }^{4}$ Qi Dai $\mathbb{D}^{5},{ }^{5}$ Yuejuan Zheng $\mathbb{D},{ }^{4}$ and Jie Lu $\mathbb{D}^{1}$ \\ ${ }^{1}$ Department of Gastroenterology, Shanghai Tenth People's Hospital, Tongji University School of Medicine, Shanghai 200072, China \\ ${ }^{2}$ The School of Medicine, Soochow University, Suzhou 215006, China \\ ${ }^{3}$ Department of Gastroenterology, Shanghai Tenth Hospital, School of Clinical Medicine, Nanjing Medical University, \\ Shanghai 200072, China \\ ${ }^{4}$ Department of Immunology and Microbiology, Shanghai University of Traditional Chinese Medicine, Shanghai 201203, China \\ ${ }^{5}$ The Eye Hospital, Wenzhou Medical University, Wenzhou City, Zhejiang 325027, China
}

Correspondence should be addressed to Qi Dai; dq@mail.eye.ac.cn, Yuejuan Zheng; 13641776412@163.com, and Jie Lu; kennisren@hotmail.com

Received 27 July 2017; Revised 14 September 2017; Accepted 28 November 2017; Published 1 February 2018

Academic Editor: Yuewen Gong

Copyright (@ 2018 Rui Kong et al. This is an open access article distributed under the Creative Commons Attribution License, which permits unrestricted use, distribution, and reproduction in any medium, provided the original work is properly cited.

Portulaca oleracea L. is a traditional Chinese medicine, which has been used as adjuvant therapy for inflammatory bowel disease (IBD). However, the mechanism of its activity in IBD still remains unclear. Since previous studies have documented the antiinflammatory effect of peroxisome proliferator activated receptors- $\gamma$ (PPAR- $\gamma$ ), Portulaca regulation of PPAR- $\gamma$ in inflammation was examined in current study. Ulcerative colitis (UC) was generated by $5 \%$ dextran sulfate sodium (DSS) in mice and four groups were established as normal control, DSS alone, DSS plus mesalamine, and DSS plus Portulaca. Severity of UC was evaluated by body weight, stool blood form, and length of colorectum. Inflammation was examined by determination of inflammatory cytokines (TNF-a, IL-6, and IL-1a). Portulaca extract was able to attenuate development of UC in DSS model similar to the treatment of mesalazine. Moreover, Portulaca extract inhibited proinflammatory cytokines release and reduced the level of DSS-induced NF- $\kappa \mathrm{B}$ phosphorylation. Furthermore, Portulaca extract restored PPAR- $\gamma$ level, which was reduced by DSS. In addition, Portulaca extract protected DSS induced apoptosis in mice. In conclusion, Portulaca extract can alleviate colitis in mice through regulation of inflammatory reaction, apoptosis, and PPAR- $\gamma$ level; therefore, Portulaca extract can be a potential candidate for the treatment of IBD.

\section{Introduction}

Inflammatory bowel disease (IBD) consists of Crohn's disease and ulcerative colitis and has been considered as a global health threat to children and adults [1]. The distribution of IBD varies in geographical regions with high incidence rate in North American and Northern Europe; however, the morbidity remains stable in these regions. In the developing regions in the world such as Asia, the incidence and morbidity are increased every year [2]. Enormous efforts have been made to find an effective therapy for IBD although current drugs including sulfasalazine, mesalamine, and corticosteroids taken alone or in combination contribute to decelerating disease progression [3]. However, with current treatments and medications, some patients suffer from side effects and complications of these drugs such as weakened immunity, infectious diseases, or increased malignant potentiality. Therefore, a promising medication with no or mild side effects is needed for IBD treatment.

Portulaca oleracea L. (Portulaca) is a traditional Chinese herb praised with rich multiminerals, proteins, $\alpha$ amyrin, $\beta$-carotene, terpenoids, vitamins, and fatty acids [4]. The medicinal properties and usage of Portulaca have been recorded in many ancient Chinese books [5]. Moreover, current researches reveal that Portulaca has several 
biological functions such as antibacteria, neuroprotection, anti-inflammation, antiatherosclerosis, and antitumor [610]. Furthermore, decoction of Portulaca has been used as a remedy for inflammatory bowel disease to alleviate symptoms of bloody stools, diarrhea, and abdominal pain in clinic. Several clinical trials have been conducted on the safety and effectiveness of Portulaca, which showed no adverse effects of Portulaca. Reports from animal studies also indicate low toxicity of Portulaca with $\mathrm{LD}_{50}$ value of $1853 \mathrm{mg} / \mathrm{kg}$ and high therapeutic index [11].

Peroxisome proliferator-activated receptor- $\gamma(\operatorname{PPAR}-\gamma)$ is an important member of the nuclear receptor superfamily. The essential role of PPAR- $\gamma$ in acute inflammation [12], adipogenesis [13], and several carcinomas has been identified [14-16]. Moreover, PPAR- $\gamma$ activation was found in various types of immune cells, including primary peritoneal macrophages, dendritic cells, and T cells [17]. Several studies have shown that activation of PPAR- $\gamma$ could downregulate some vital proinflammatory cytokines, such as IL-1 $\beta$, IL-2, IL-6, and TNF- $\alpha$ [18] as well as inhibition of NF- $\kappa$ B phosphorylation in monocyte and other types of cells. Therefore, activation of PPAR- $\gamma$ exerts a direct anti-inflammatory effect in IBD, while the mechanism of PPAR- $\gamma$ activation remains to be further explored [19].

In the current study, the anti-inflammatory activity and mechanism of Portulaca in dextran sulfate sodium (DSS) induced UC animal model were explored.

\section{Materials and Methods}

2.1. Plant Material and Preparation of the Extracts. The Portulaca material was obtained from the Department of Traditional Chinese Medicine Pharmacy of the Shanghai Tenth People's Hospital. The herb was triturated into powder and water-soluble substance was extracted as described previously [20]. Briefly, the prepared powder was boiled in distilled water $\left(80^{\circ} \mathrm{C}, 25 \mathrm{~g} / 120 \mathrm{ml}\right.$ water, w/v) for $60 \mathrm{~min}$ and then smashed via ultrasonic concussion ( 3 cycles of $15 \mathrm{sec}$ ). The mixture of water and concussion was filtered using $2 \mathrm{~mm}$ pores strainer and the resultant material was lyophilized under vacuum.

2.2. Animals and Acute Colitis Induction. Forty adult female mice weighting 18-22 g were purchased from the Shanghai Laboratory Animal Co., Ltd. (Shanghai, China), and maintained in an environment of $25^{\circ} \mathrm{C}$ with controlled $12 \mathrm{~h}$ light/dark cycle. Mice were permitted free access to water and standard mouse chow. The animal protocol was approved by the Ethics Committee of the Tongji University, which meets the recommendations in the Guide for Care and Use of Laboratory Animals of the National Institutes of Health. The dextran sulfate sodium reagent (molecular weight: 36,000-50,000 from MP Biochemicals Solon, OH, USA) was diluted with drinking water to make final concentration of $3 \%$.

The mice were divided into 4 groups at random:

(1) Normal control: given normal food and water for 7 days
TABLE 1: DAI assessment (disease activity index).

\begin{tabular}{lccc}
\hline $\begin{array}{l}\text { Weight } \\
\text { loss } \%\end{array}$ & Shape of stool & $\begin{array}{c}\text { FOBT }^{*} / \\
\text { blood stool }\end{array}$ & Score \\
\hline 0 & Normal & Normal & 0 \\
$1-5$ & Shapeless stool & FOBT positive & 1 \\
$6-10$ & Loose stool & Gross blood stool & 3 \\
$11-15$ & & & 4 \\
$>16$ & & &
\end{tabular}

${ }^{*}$ FOBT: fecal occult blood test.

(2) DSS group: 3\% DSS + saline by gavage for 7 days

(3) Mesalamine positive control group: 3\% DSS + $7.4 \mathrm{mg} / \mathrm{kg}$ mesalamine daily by gavage for 7 days

(4) Portulaca group: $3 \% \mathrm{DSS}+100 \mathrm{mg} / \mathrm{kg}$ daily by gavage for 7 days

During the period of modeling, mice weight, stool form, and stool occult blood were recorded every day to assess the disease activity index (DAI) of acute colitis; the evaluative criteria were clarified in Table 1.

2.3. Serum Cytokine Analysis. The serum levels of TNF- $\alpha$, IL$1 \beta$, and IL- 6 concentrations were determined by using ELISA Kits (Elabscience, Wuhan, China), respectively, according to the manufacturer's instruction. The OD values of absorbance at $450 \mathrm{~nm}$ were examined by ThermoMax microplate reader.

2.4. Determination of MPO (Myeloperoxidase) Activity in Serum Sample. Myeloperoxidase is found in activated neutrophils and macrophages, which plays a defensive role during inflammatory response via catalyzing hydrogen peroxide into hypochlorous acid. The serum samples reacted with the mixed solution including $3,3^{\prime}$-dimethoxybiphenyl-4, $4^{\prime}$ diamine and hydrogen peroxide, $\mathrm{pH} 6.0$, according to the MPO assay kit (Nanjing Jiancheng Bioengineering Institute, A044, China). The absorbance of control well and testing well at $460 \mathrm{~nm}$ was determined by microplate reader. The activity of MPO was calculated as the following formula:

$$
\begin{aligned}
& \text { MPO performance (U/L) } \\
& =\frac{(\text { testing OD values }- \text { control OD values) }}{11.3} \\
& \quad \times \text { sample volume }(\mathrm{L})
\end{aligned}
$$

2.5. Fecal Occult Blood Testing. The form of stool was recorded and the severity of stool occult blood was analyzed by urine fecal occult blood test kit (Nanjing Jiancheng Bioengineering Institute, C027, China). A small amount of feces samples was picked and smeared on the slides. Add orthotolidine and hydrogen peroxide reagent on the surface of stool samples. The results were analyzed according to the indications: negative (-): the samples do not show color within 3 minutes; weakly positive $(+)$ : the samples show blue within 30 to 60 seconds; positive $(++)$ : the samples appear 
TABLE 2: The sequence of primers used in experiments.

\begin{tabular}{|c|c|c|}
\hline Gene & Primer sequence $\left(5^{\prime}-3^{\prime}\right)$ & $\begin{array}{c}\text { Annealing } \\
\text { temperature } \\
\left({ }^{\circ} \mathrm{C}\right)\end{array}$ \\
\hline \multicolumn{3}{|c|}{ GADPH } \\
\hline $\mathrm{F}$ & GGACCTCATGGCCTACATGG & \multirow{2}{*}{57.6} \\
\hline $\mathrm{R}$ & TAGGGCCTCTCTTGCTCAGT & \\
\hline \multicolumn{3}{|l|}{ IL-6 } \\
\hline $\mathrm{F}$ & GGCGGATCGGATGTTGTGAT & \multirow{2}{*}{57.3} \\
\hline $\mathrm{R}$ & GGACCCCAGACAATCGGTTG & \\
\hline \multicolumn{3}{|l|}{ IL-1 $\beta$} \\
\hline $\mathrm{F}$ & CTTTGAAGTTGACGGACCC & \multirow{2}{*}{53.1} \\
\hline $\mathrm{R}$ & TGAGTGATACTGCCTGCCTG & \\
\hline \multicolumn{3}{|c|}{ TNF- $\alpha$} \\
\hline $\mathrm{F}$ & CACCACCATCAAGGACTCAA & \multirow{2}{*}{54.5} \\
\hline $\mathrm{R}$ & AGGCAACCTGACCACTCTCC & \\
\hline \multicolumn{3}{|c|}{ PPAR- $\gamma$} \\
\hline $\mathrm{F}$ & CCCAATGGTTGCTGATTACA & \multirow{2}{*}{54.4} \\
\hline $\mathrm{R}$ & GGACGCAGGCTCTACTTTGA & \\
\hline \multicolumn{3}{|c|}{$\mathrm{NF} \kappa \mathrm{Bp} 65$} \\
\hline $\mathrm{F}$ & TGCGATTCCGCTATAAATGCG & \multirow{2}{*}{60.2} \\
\hline $\mathrm{R}$ & ACAAGTTCATGTGGATGAGGC & \\
\hline \multicolumn{3}{|l|}{ Bax } \\
\hline $\mathrm{F}$ & AGACAGGGGCCTTTTTGCTAC & \multirow{2}{*}{57.3} \\
\hline $\mathrm{R}$ & AATTCGCCGGAGACACTCG & \\
\hline \multicolumn{3}{|l|}{$\mathrm{Bcl}-2$} \\
\hline $\mathrm{F}$ & GAGCCTGTGAGAGACGTGG & \multirow{2}{*}{57.3} \\
\hline $\mathrm{R}$ & CGAGTCTGTGTATAGCAATCCCA & \\
\hline
\end{tabular}

bluish green; strongly positive (+++): samples show mazarine immediately.

2.6. Gene Expression Analysis by Real-Time Reverse Transcriptase Polymerase Chain Reaction. Total RNA was extracted from fresh colorectum tissues by the Trizol reagent from the Thermo Fisher Scientific (Waltham, MA, USA) and washed by $75 \%$ ethanol. One microgram total RNA was transcribed into cDNA using reverse transcription kit (Takara Biotechnology, Dalian, China). The first transcribed cDNA was diluted ten times and applied to real-time polymerase chain reaction (SYBR Premix EX Taq, Takara Biotechnology) with the following cycle of denaturing at $94^{\circ} \mathrm{C}$ for 30 seconds, annealing at different temperature according to the primers for 30 seconds and elongation at $72^{\circ} \mathrm{C}$ for 45 seconds using a 7900 HT Fast Real-Time PCR System (Thermo Fisher Scientific). All primers used in experiments were listed in Table 2.

2.7. Hematoxylin and Eosin Staining. Fresh colorectum tissues were fixed in formalin and embedded in paraffin. The tissue blot was cut into $4 \mu \mathrm{m}$ thick section for histological examination using hematoxylin and eosin $(\mathrm{H} \& \mathrm{E})$. The injury index of histology was evaluated according to three aspects: the destructive degree of the intestine epithelium, the presence of the immune cell infiltration in intestine mucosa, and the infiltration degree of immune cell in submucosa. The histology score was depicted in Table 3. Two experienced pathologists made the assessment independently.

2.8. Western Blotting Analysis. Total protein was extracted from fresh colorectum tissue by cell lysis buffer with protease and phosphatase inhibitor mixture (New Cell \& Molecular Biotech Co., Ltd., China). The protein quantification was determined by BCA methods (Beyotime, Shanghai, China). Equal amount of protein $(25 \mathrm{ug})$ from each sample was loaded on to $12 \%$ SDS-PAGE. After separation through electrophoresis, the proteins were transferred onto PVDF membranes (Millipore Corp, Billerica, MA, USA). The membranes were then incubated with 5\% nonfat milk in tris-buffered saline (TBS) to block nonspecific binding with antibody. The membranes were then incubated with primary antibodies at $4^{\circ} \mathrm{C}$ overnight. The primary antibodies used in experiments were as follows: $\beta$-actin, PPAR- $\gamma, \mathrm{NF}-\kappa \mathrm{B}, \mathrm{pNF}-\kappa \mathrm{B}$ (all from Cell Signaling Technology, Danvers, MA, USA), Bcl-2, Bax (all from Proteintech Group, Inc., Chicago, IL, USA), and caspase 3 (Cell Signaling Technology, Danvers, MA, USA) with dilution of $1: 1000,1: 1000,1: 1000,1: 500,1: 500$, and $1: 1000$, respectively. After incubation with primary antibody, the membranes were washed three times with TBST and then incubated with the appropriate horseradish peroxidaseconjugated secondary antibodies. The signals were detected and the intensity of bands was analyzed by Odyssey.

2.9. Immunohistochemical Staining. Tissue specimen collected from mice was fixed in $4 \%$ paraformaldehyde overnight and embedded in paraffin. Sections $(4 \mu \mathrm{m})$ were dewaxed and hydrated through serial graded xylene ethanol. After being washed with phosphate-buffered saline (PBS) solution three times, antigen retrieval was performed using a microwave with heating to $95^{\circ} \mathrm{C}$ and cooling to room temperature (four times). Primary antibody PPAR- $\gamma$ (Cell Signaling Technology, Danvers, MA, USA) was diluted into working concentration and then incubated with the slices at $4^{\circ} \mathrm{C}$ overnight. Following incubation of secondary antibody, $\mathrm{DAB}$ substrate was used as the chromogen. Positive expression areas were observed under microscope.

2.10. Statistical Analysis. The statistical analysis was performed using the SPSS 20.0 software package (IBM Corporation, Armonk, NY, USA). All values were expressed with the mean \pm standard deviation using the Student-Newman-Keuls test or one-way analysis of variance. A $p$ value $<0.05$ was considered statistically significant. The positively stained areas of IHC were evaluated and analyzed using Image-Pro Plus 6.0 software (Media Cybernetics, Silver Spring, MD, USA).

\section{Results}

3.1. Portulaca Extract Decreases the Disease Activity Index, the Length of Colorectum, and Myeloperoxidase Activity of Dextran Sulfate Sodium Induced Colitis. Since severity of 
TABLE 3: Histology scoring.

\begin{tabular}{lcc}
\hline Lesions of colonic epithelium & $\begin{array}{c}\text { Granulocyte infiltration } \\
\text { of intestine mucosa }\end{array}$ & $\begin{array}{c}\text { Granulocyte infiltration } \\
\text { of submucosa }\end{array}$ \\
\hline Normal & Normal & Normal \\
Cellular proliferation/anomalous crypt/absence of goblet cell & Mild & Mild to moderate \\
Absence of intestinal crypt (10\%-50\%) & Moderate & Severe \\
Absence of intestinal crypt (50\%-90\%) & Severe & 2 \\
Entire absence of intestinal crypt with integral epithelia & & 3 \\
Mild to moderate ulceration epithelia & & 4 \\
Severe ulceration & & 6 \\
\hline
\end{tabular}

colitis is evaluated by the DAI, MPO, and the length of colorectum, the effects of Portulaca extract on these parameters were examined. As shown in Figure 1(b), mice in DSS group have significant higher DAI than those in all other groups starting from day $3(p<0.05)$. Mice in Portulaca extract and mesalamine groups showed higher DAI starting from day 3 and reaching to the peak at day 5 compared to those in normal control. After day 5, DAI was gradually decreased although they were still higher than that in normal control. Since DAI consists of three aspects including weight loss, diarrhea, and the bloody stool scores. The weight loss and bloody stool scores were further evaluated and shown in Figures 1(c) and 1(d). DSS induced ulcerative colitis and significantly reduced body weight of the mice in DSS group $(p<0.01)$. However, the treatment of Portulaca extract and mesalamine significantly restored the body weights as shown in the Portulaca and mesalamine groups. In addition, there was a higher bloody stool score in DSS group than all other groups. Treatment of Portulaca and mesalamine reduced the score (Figure $1(\mathrm{~d})$ ).

The length of colorectum was an evaluation content of colitis, which means the total length from cecum to anus of mice. Compared with that of control group, there was a significant decrease in the length of colorectum in DSS group $(p<0.0001)$. But the length of colorectum in mesalamine and Portulaca group was longer than that in DSS group (Figure 1(e)). Moreover, myeloperoxidase (MPO) serves as an independent predictor for oxidative stress and inflammatory reactions. The average MPO activity in mice of control group was $0.56 \pm 0.05 \times 10^{-3} \mathrm{U} / \mathrm{ml}$, while DSS exposure increased the MPO activity to $2.19 \pm 0.82 \times 10^{-3} \mathrm{U} / \mathrm{ml}$. The treatment of mesalamine and Portulaca group reduced the MPO activity to $0.84 \pm 0.11 \times 10^{-3} \mathrm{U} / \mathrm{ml}$ and $0.71 \pm 0.04 \times 10^{-3} \mathrm{U} / \mathrm{ml}$ respectively (Figure 1(f)).

\subsection{Effect of Portulaca Extract on Proinflammatory Cytokines} Expression and Colorectum Injury. Since DSS induced ulcerative colitis, the expressions of three proinflammatory cytokines (TNF- $\alpha$, IL-6, and IL-1 $\beta$ ) were examined in the serum and colorectum tissue. As shown in Figures 2(a) and 2(b), there were significant increases in all three proinflammatory cytokines at both mRNA and protein levels $(p<$ 0.05). Moreover, treatment of Portulaca and mesalamine significantly reduced the DSS-induced cytokine expression at both mRNA and protein levels $(p<0.05)$. Two independent experienced pathologists examined the tissue injury of colorectum. The injury score resulted from the evaluation of enterocyte lessons and inflammatory cell infiltration in mucosa and submucosa regions. Figure 2(c) showed $\mathrm{HE}$ staining of colorectum tissues from mice of four different groups with magnification of $200 x$ in the upper row and different magnification of colorectum in DSS mice. There was a significant increase in tissue injury score in DSS mice compared to all other mice $(p<0.0001)$. Treatment of Portulaca extract and mesalamine resulted in lesser enterocyte lesions and inflammatory cell infiltration in mucosa and submucosa (Figures 2(c) and 2(d)).

3.3. Regulation of NF- $\kappa B$ and PPAR- $\gamma$ by Portulaca Extracts in Colorectum. Both NF- $\kappa$ B and PPAR- $\gamma$ play an important role in inflammation, activation of NF- $\kappa \mathrm{B}$ is the critical step to increase the expression of different inflammatory cytokines such as TNF- $\alpha$. Moreover, previous studies documented that PPAR- $\gamma$ could antagonize inflammatory responses through inhibition of transcriptional activation of inflammatory response genes such as transcriptional factor NF- $\kappa \mathrm{B}$. Therefore, the expressions of NF- $\kappa \mathrm{B}$ and PPAR- $\gamma$ were examined in the study. Figure 3(a) showed the staining of PPAR- $\gamma$ in colorectum tissues from mice of four different groups. Significant reduction of PPAR- $\gamma$ staining was observed in the colorectum of mice in DSS groups, while treatment of either Portulaca extract or mesalamine restored back the staining of PPAR- $\gamma$ in the colorectum. Figure 3(b) displayed both NFkBp65 and PPAR $-\gamma$ proteins by western blot and Figure 3(c) showed the mRNA levels of both NF-kB and PPAR- $\gamma$. There was significant decrease in PPAR- $\gamma$ expression at both mRNA and protein levels in DSS group compared to that in normal control group $(p<0.05)$. Both Portulaca extract and mesalamine restored PPAR- $\gamma$ levels back to that in normal control group. DSS treatment significantly induced NF-kB expression at both mRNA and protein levels $(p<0.05)$, while treatments of either Portulaca extract or mesalamine brought NF-kB levels back to that in normal control group.

3.4. Regulation of Apoptosis Protein in Colorectum by Portulaca Extract. Inflammatory reaction usually results in cell death; however whether it is through apoptosis or necrosis remains to be explored. In the current study, three apoptotic proteins were examined including proapoptotic proteins (Bax 


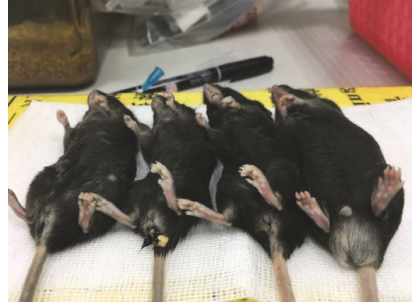

(a)

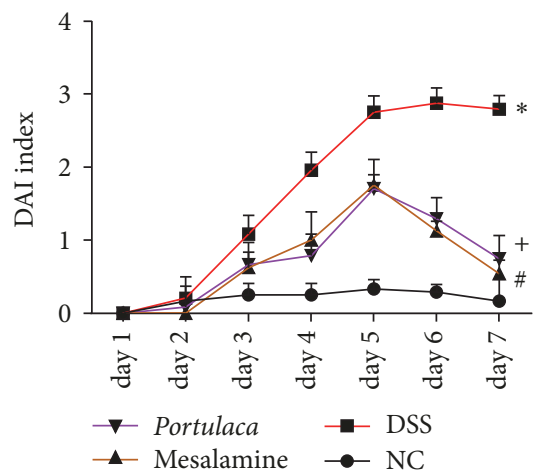

(b)

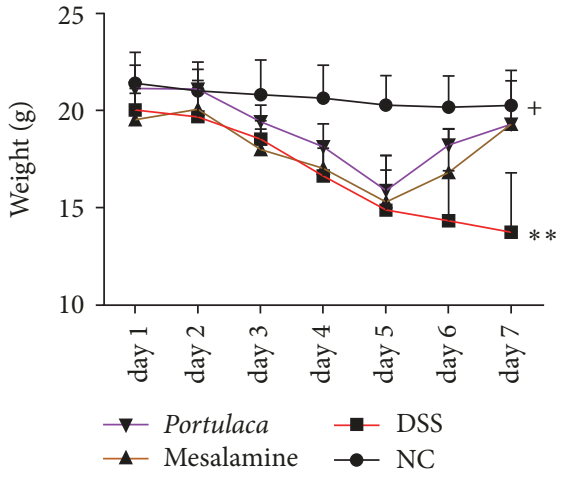

(c)
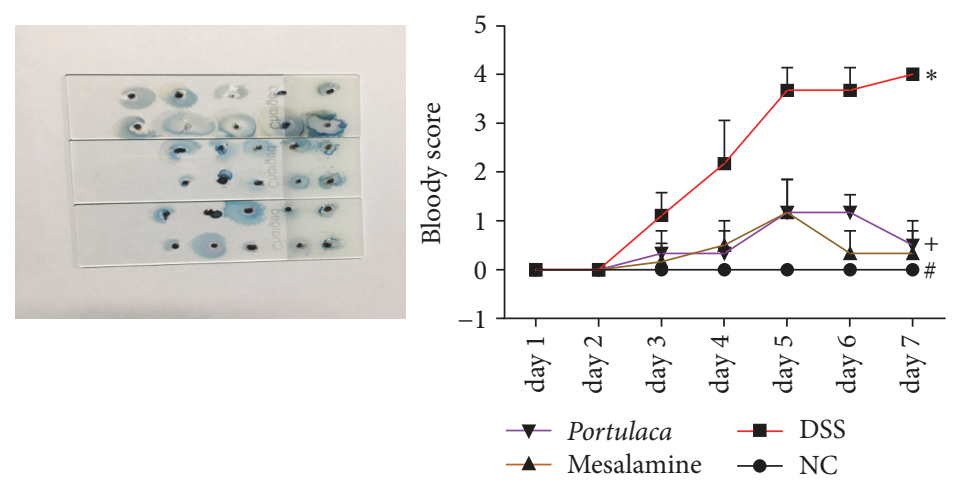

(d)

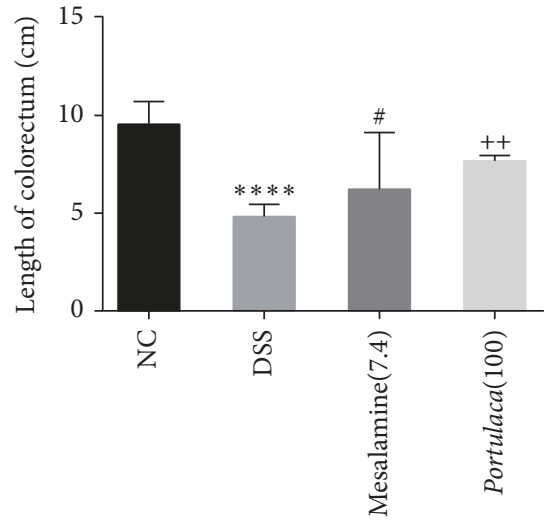

(e)

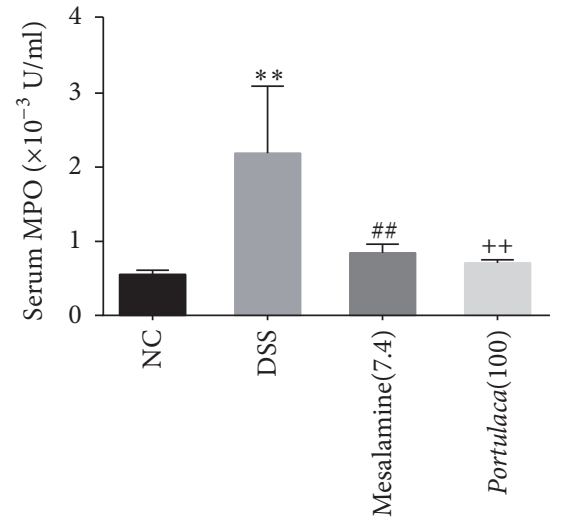

(f)

FIGURE 1: Effect of Portulaca treatment on disease severity of DSS-induced UC model. Panel (a) shows the appearance of representative mice from four experiment groups from left to right: control group, DSS-induced group, mesalamine group, and Portulaca group. Panel (b) displays the graph of disease activity index (DAI) of four groups at different days of the experiment. Panel (c) represents the weight of mice daily in different group. Panel (d) shows the image of fecal occult blood testing at 8th day with the darker color and more severe bloody stool and shows the score of bloody stool at different days of each group. Panel (e) represents the length of colorectum from four groups at 8 th day after DSS administration. Panel (f) indicates the MPO activity in serum. (Data were presented as mean \pm SD from six rats. * indicates comparison between DSS and NC; \# indicates comparison between mesalamine and DSS; + indicates the comparison between Portulaca and DSS. The number of symbols indicates significance of difference; for example, four symbols indicate $p<0.0001$; three symbols indicate $p<0.001$; two symbols indicate $p<0.01$; and one symbol indicates $p<0.05$.)

and cleaved caspase 3 ) and antiapoptotic protein (Bcl-2). As shown in Figure 4, abundance of Bcl-2, Bax, and caspase 3 was documented by western blot analyses. There was significant decrease in Bcl-2 level $(p<0.001)$ but significant increase in Bax level in colorectum of mice in DSS group compared to all other groups $(p<0.0001)$. Although whole caspase 3 showed no change in the colorectum of mice in DSS group, the cleaved form of caspase 3 was significantly increased $(p<0.01)$. All these changes were corrected after treatment of either Portulaca extract or mesalazine. Moreover, mRNA levels of Bcl-2 and Bax showed the same changes as their proteins in the four different groups of mice. 

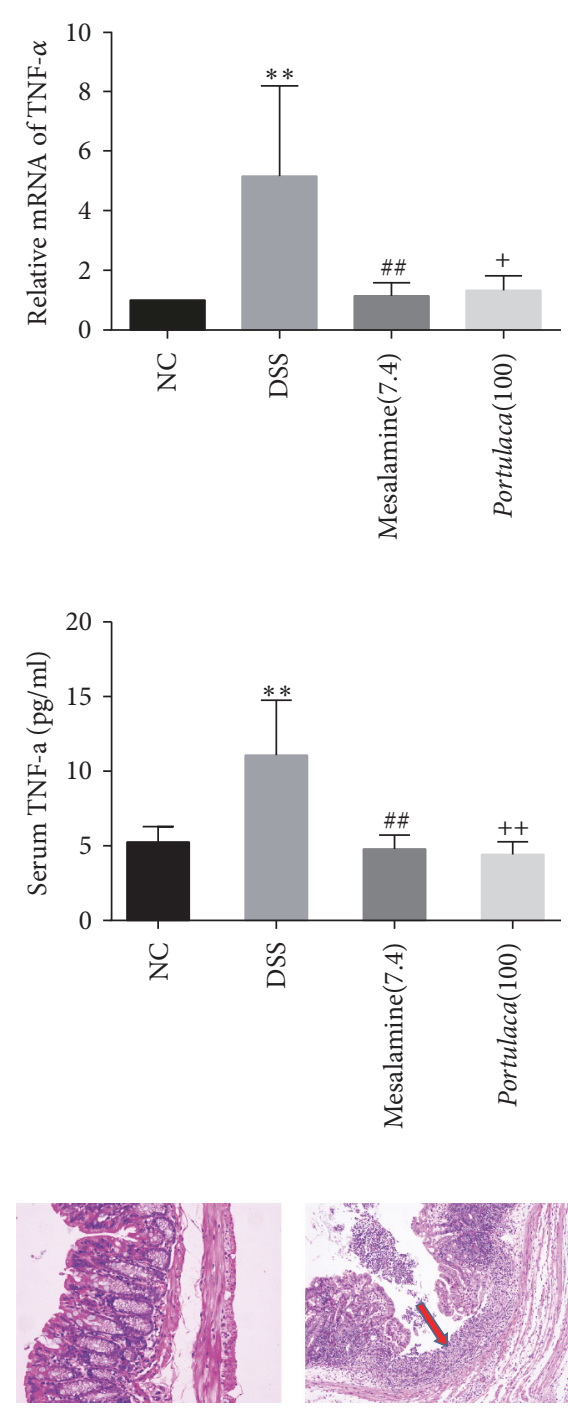

200x DSS

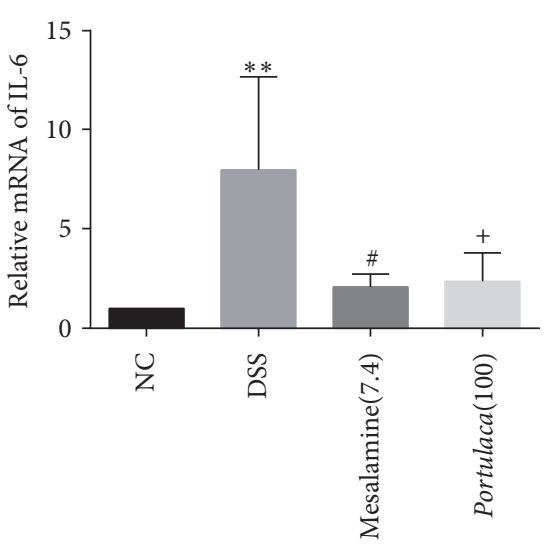

(a)

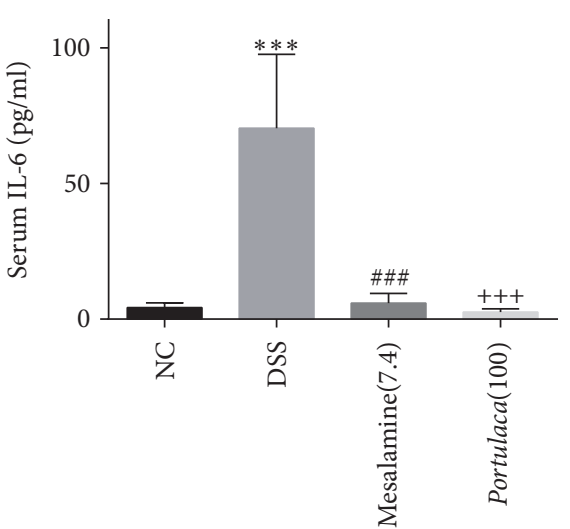

(b)

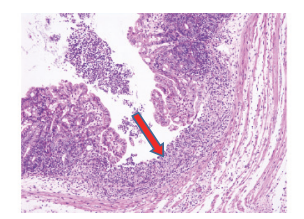

200x NC

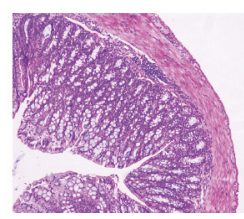

200x M

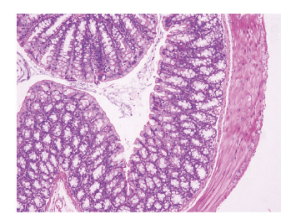

200x P

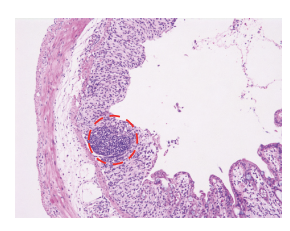

100x DSS

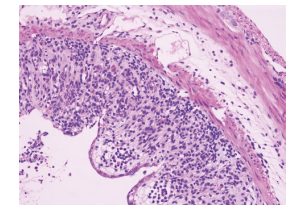

200x DSS

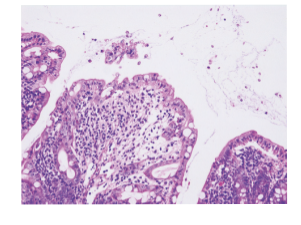

400x DSS (c)
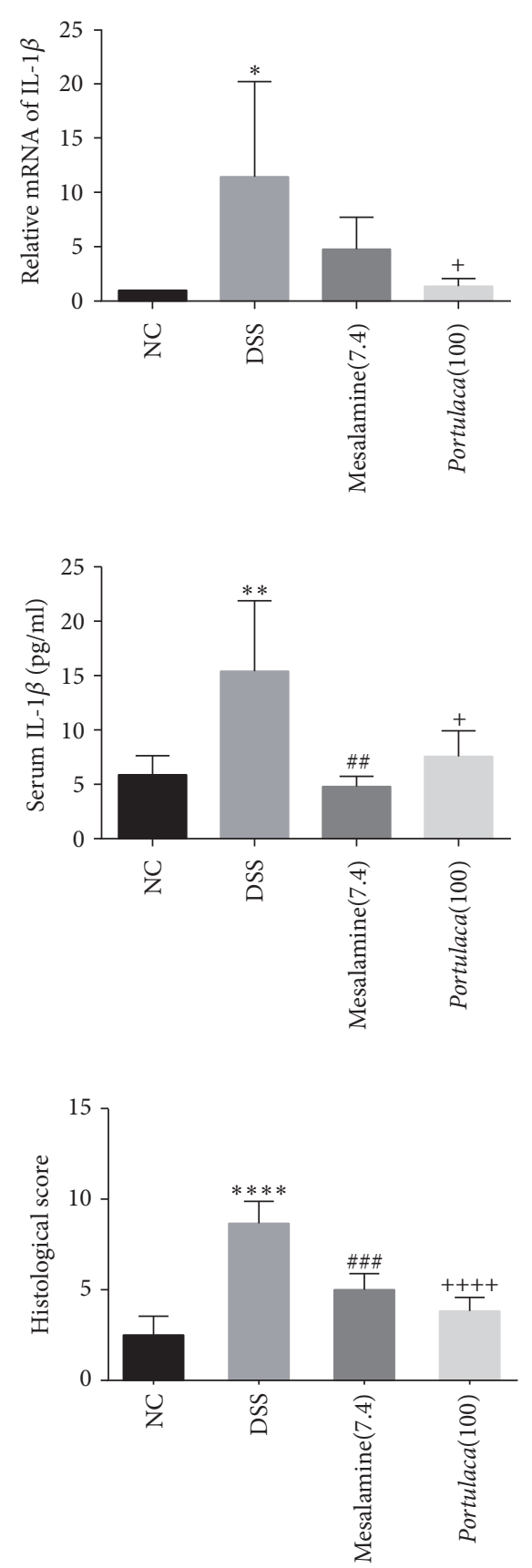

(d)

Figure 2: Effect of Portulaca extract on serum cytokines and tissue injury scores of DSS-induced acute colitis. Panel (a) indicates that the mRNA expressions of TNF- $\alpha$, IL-6, and IL- $1 \beta$ were evaluated in each group with qRT- PCR. Panel (b) shows that the levels of TNF- $\alpha$, IL-6, and IL-1 $\beta$ in serum were detected via ELISA assay. Panel (c) displays the H\&E stained colon images (NC refers to negative control; DSS refers to DSS alone group; M refers to mesalamine group; P refers to Portulaca group). The dotted potion indicated the hyperplasia of lymphoid follicle; red arrow pointed the infiltration of inflammatory cells. Panel (d) indicates the histological scores of H\&E stained colorectum images. (Data were presented as mean \pm SD from six rats. * indicates comparison between DSS and NC; \# indicates comparison between mesalamine and DSS; + indicates the comparison between Portulaca and DSS. The number of symbols indicates significance of difference; for example, four symbols indicate $p<0.0001$; three symbols indicate $p<0.001$; two symbols indicate $p<0.01$; and one symbol indicates $p<0.05$.) 


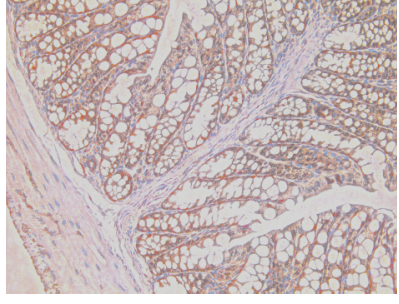

200x NC

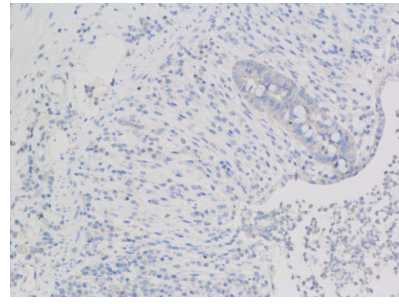

200x DSS

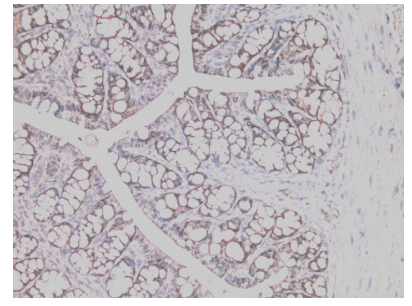

200x M

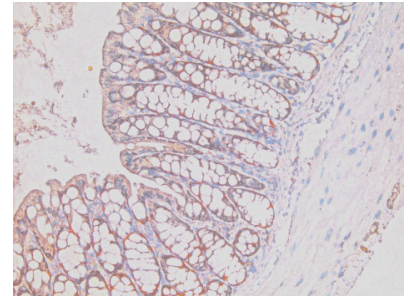

200x P

(a)
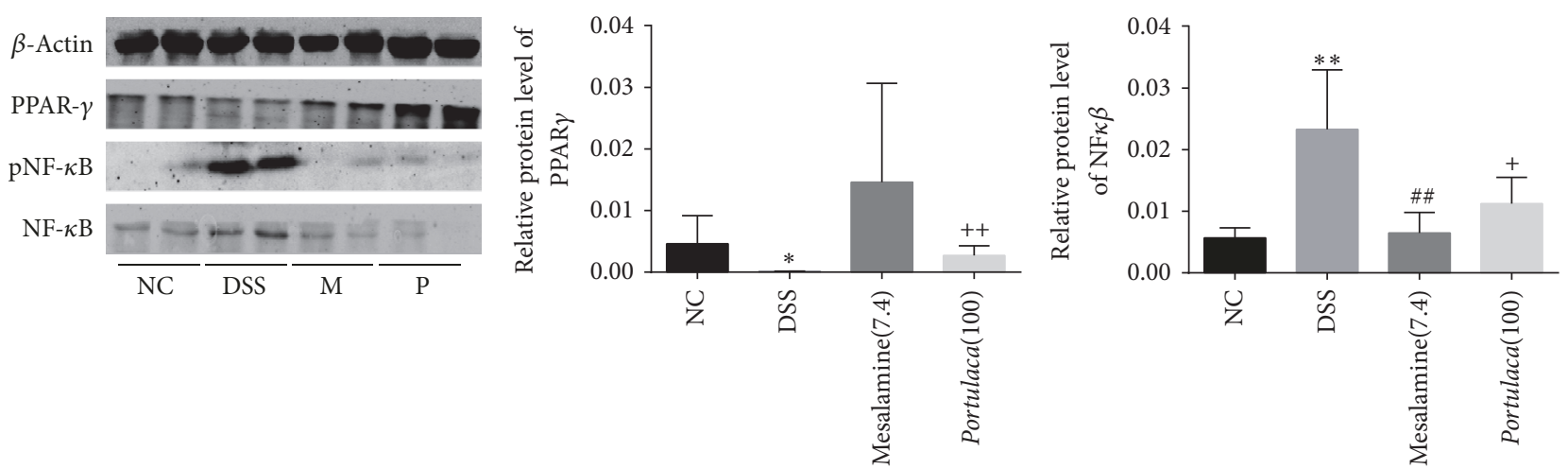

(b)
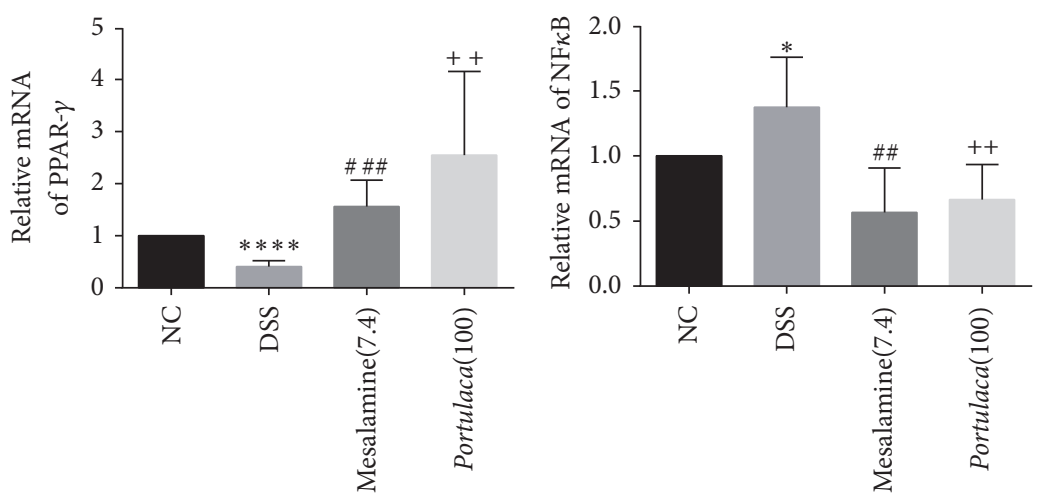

(d)

FIgURE 3: Effect of Portulaca extracts on NF- $\kappa$ B and PPAR- $\gamma$ expression in colonic tissue. Panel (a) represents the immunohistochemistry staining of PPAR- $\gamma$. (NC refers to negative control; DSS refers to DSS alone group; M refers to mesalamine group; P refers to Portulaca group, original magnification: $\times 200$ ). Panel (b) shows the expression of PPAR- $\gamma, \mathrm{NF}-\kappa \mathrm{B}$, and pNF- $\kappa \mathrm{B}$ in colorectum tissues from western blot. Panel (c) shows the histograms of grey intensity for PPAR- $\gamma$ and NF- $\kappa$ B relative to $\beta$-actin. Panel (d) shows the relative mRNA expression of PPAR$\gamma$ and NF- $\kappa$ B from quantitative real-time PCR. (Data are presented as mean \pm SD from six experiments. $*$ indicates comparison between DSS and NC; \# indicates comparison between mesalamine and DSS; + indicates the comparison between Portulaca and DSS. The number of symbols indicates significance of difference; for example, four symbols indicate $p<0.0001$; three symbols indicate $p<0.001$; two symbols indicate $p<0.01$; and one symbol indicates $p<0.05$.)

\section{Discussion}

Inflammatory bowel disease commonly presents with intestine and extraintestine manifestations [21]. The typical symptom of IBD clinically is the blood and mucus mixed with stool. Other symptoms may include fevers, weight loss, arthritis, mucocutaneous lesions, and extraintestine presentations, which are useful for diagnosis, evaluating patient's condition and drug selection [22]. In the current study, weight loss and feces changes accompanied by blood and mucus mixed with stool were recorded daily to estimate the DAI (disease activity index) of the colitis. Significant high index of DAI in DSS-induced UC mice in the current study indicates successful establishment of UC model in mice. Moreover, with this model, therapeutic activity of Portulaca extract was also demonstrated showing that mice with treatment of Portulaca extract had significant lower DAI index than that without Portulaca treatment. Furthermore, with this successful model of UC, the effect of Portulaca extract on the length of colorectum was also documented. 


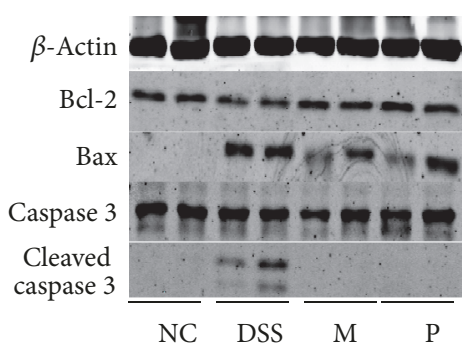

(a)
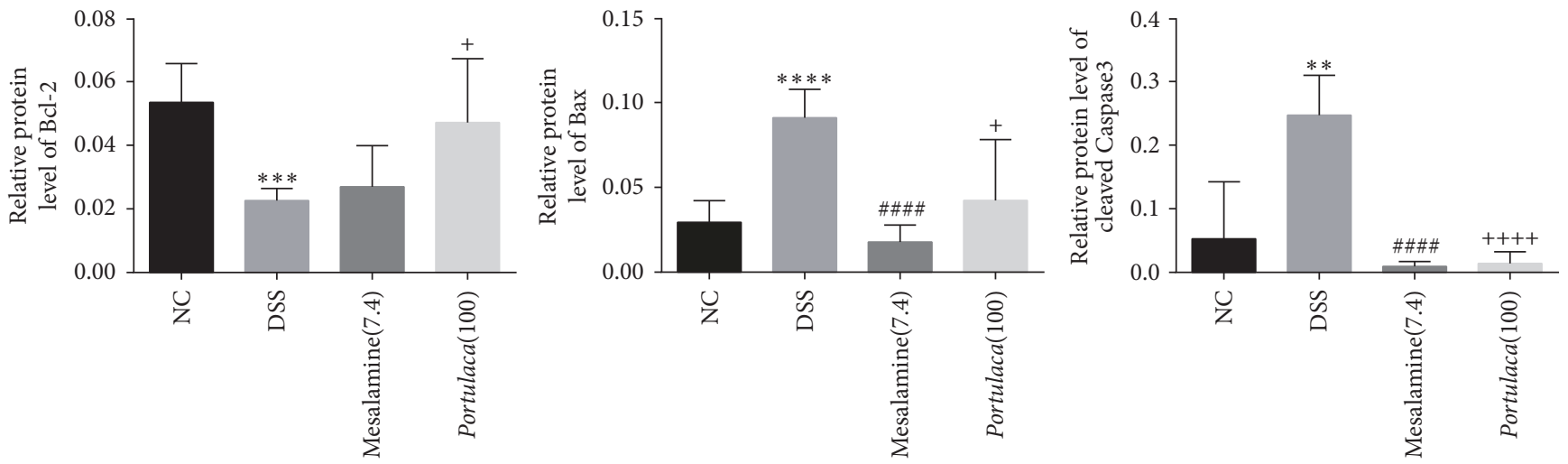

(b)
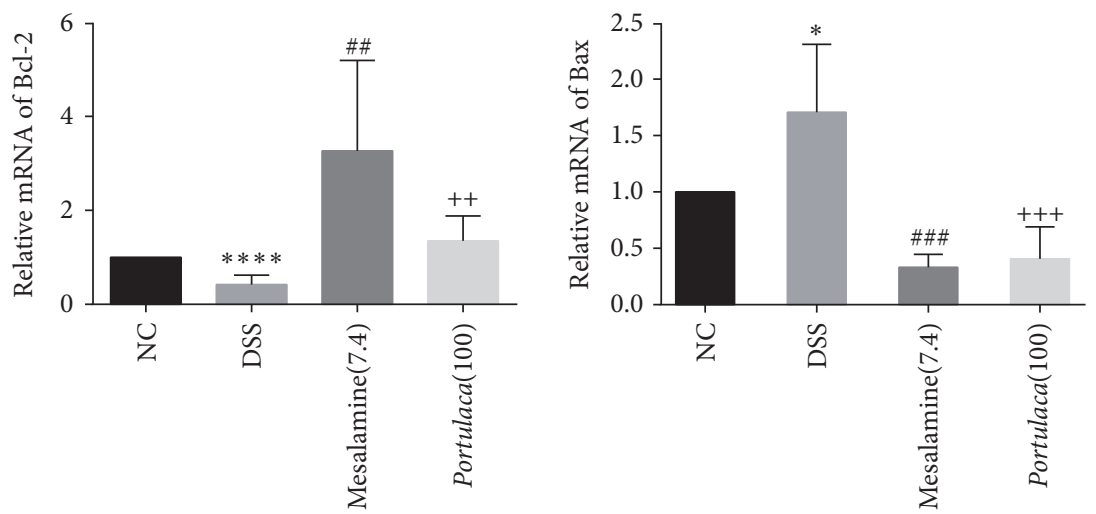

(c)

Figure 4: Effects of Portulaca extract on apoptosis in mice on inflammatory bowel disease. Panel (a) shows the protein level of Bcl-2, Bax, caspase 3, and cleaved caspase 3 in each group. Panel (b) represents the histogram of density for Bcl-2, Bax, and cleaved caspase 3. Panel (c) represents the relative mRNA level of Bcl-2 and Bax from quantitative real-time PCR, respectively. (Data are presented as mean \pm SD from six experiments. * indicates comparison between DSS and NC; \# indicates comparison between mesalamine and DSS; + indicates the comparison between Portulaca and DSS. The number of symbols indicates significance of difference; for example, four symbols indicate $p<0.0001$; three symbols indicate $p<0.001$; two symbols indicate $p<0.01$; and one symbol indicates $p<0.05$.)

Mice with DSS-induced UC showed shorter colorectum than normal mice, which is consistent with the report of UC [23]. Treatment of Portulaca extract could also increase the length of colorectum in rats with DSS-induced colitis. The findings indicate that Portulaca extract could ameliorate general symptoms of IBD.

Currently, myeloperoxidase activity is considered as an independent indicator of inflammation and oxidative stress. This enzyme in leukocyte usually has the capacity to catalyze the hydrogen peroxide [24]. Clinically, myeloperoxidase activity has been used to predict inflammation and oxidative stress in renal failure [25], myocardial infarction [26], inflammatory vascular disease [27], and so on. Consistent with these reports, higher level of MPO was observed in mice of DSS treatment, which induces inflammation and ulcerative colitis in the intestine [28]. This elevation of MPO in serum is also consistent with intestine injury score observed in the colorectum tissues especially the infiltration of inflammatory cells in the mucosa and submucosa. These findings suggest that MPO could be an indicator for either DSS-induced colitis or clinical presentation of IBD.

Several immune cells and immune-regulatory proteins participated in the disturbance of intestine immune system, which account for activation and augmentation of 
inflammation cascade in IBD. The intestinal epithelial cells usually act as the first barrier for any intestinal disorders [29]. Once the epithelial cells are injured by external stress, intestine pathogens may enter the intestine, which triggers antigen-presenting cells and transform naive $\mathrm{T}$ cells into effector $\mathrm{T}$ cells such as Th1, Th17, Th2, and natural killer $\mathrm{T}$ cells. These cells are responsible for generating multiple types of proinflammatory cytokines [30]. Moreover, these cells could secret interferon $\gamma$, interleukin $1 \beta$, and other cytokines to activate macrophages, which in turn could secrete large amounts of cytokines including tumor necrosis factor $\alpha$, interleukin 1, and interleukin 6. Furthermore, several cell types in the process such as dendritic cells, mast cells, and leucocytes can also promote the dysfunction of innate and adaptive immune response of inflammatory disease [31]. In current study, we found application of Portulaca could significantly reduce the expression levels of these cytokines including TNF- $\alpha$, IL- 6 , and IL- $1 \beta$. These findings suggested that Portulaca may affect $\mathrm{T}$ cell activation and participate in inflammation to some extent.

In present study, three proinflammatory cytokines (TNF$\alpha$, IL-6, and IL-1 $\beta$ ) were examined. These cytokines are mainly released by macrophages and differentiated $\mathrm{T}$ cells [32]. In addition, TNF- $\alpha$ could also exert its inflammation response through upregulation of IL-1 $\beta$ and IL- 6 and induce tissue damage through necrosis and apoptosis [33] and activate NF- $\kappa \mathrm{B}$ [34]. Moreover, all three cytokines are able to exert other functions by interacting with other molecules through different pathway. The findings of TNF- $\alpha$, IL- $1 \beta$, and IL- 6 in the current study are in line with the reports in patients with either UC or CD $[35,36]$.

Except cytokines, transcriptional factors are also important in regulation of inflammation. The transcriptional factor NF- $\kappa$ B is known to regulate the level of TNF- $\alpha$, IL- 6 , and IL$1 \beta$ during the progression of inflammatory bowel disease [37]. Moreover, NF- $\kappa \mathrm{B}$ can facilitate cell apoptosis through the upregulation of c-FLIP level while lowering the expression of antiapoptotic proteins such as Bcl-2, Bcl-xl, c-IAP1/2, and $\mathrm{x}$-IAP [38]. In the present study, overexpressed TNF$\alpha$, IL- 6 , IL- $1 \beta$, and pNF- $\kappa$ B were observed in DSS treated mice, which indicate an enhanced inflammatory process and aggravated tissue damage. On the contrary, the addition of Portulaca extract reduced inflammation response and tissue damage indicating a role of Portulaca extract in prevention and treatment of inflammatory bowel disease.

PPAR- $\gamma$ is another transcription factor, which plays an important role in adipogenesis, glucose metabolism [39], and anti-inflammatory reaction. Several reports suggest that PPAR- $\gamma$ agonists may have beneficial effects for the inflammatory diseases, including mastitis, IBD, and arthritis [4042]. Jiang et al. observed that PPAR agonist (15d-PGJ ${ }_{2}$ ) could abrogate the production of proinflammatory cytokines TNF$\alpha$ and interleukin-6 [43]. Moreover, the NF- $\kappa \mathrm{B}$ activation is inhibited after PPAR- $\gamma$ agonist due to changes of conformation in NF-kB subunits. The findings from the current study also observed that PPAR- $\gamma$ level was increased in DSS-induced group following Portulaca extract intervention together with suppressed cytokines and NF- $\kappa \mathrm{B}$.
The mechanism of apoptosis in IBD remains controversial. Some studies observed an increased apoptosis in lamina propria (LP) and epithelium, which contributed to the severity of UC [44]. Moreover, activation of PPAR- $\gamma$ could attenuate the cascade of apoptosis [45]. In the current study, antiapoptosis protein (Bcl-2) was decreased and proapoptosis proteins (Bax and cleaved caspase 3) were increased in UC mice. However, treatment of Portulaca extract reverses apoptosis in the colorectum. This finding suggests further investigation of apoptosis and Portulaca in inflammatory bowel disease.

\section{Conclusion}

With the successful model of inflammatory bowel disease, Portulaca extract was demonstrated to reduce severity of the disease. The mechanism of Portulaca extract in alleviation of inflammatory bowel disease could be related to its regulation of inflammatory cytokines (TNF- $\alpha$, IL-6, and IL-1 $\beta$ ), transcription factors (NF-kB and PPAR- $\gamma$ ), and apoptosis. Therefore, Portulaca extract might be a potential agent for the treatment of patients with inflammatory bowel disease.

\section{Conflicts of Interest}

The authors declare that there are no conflicts of interest regarding the publication of this paper.

\section{Authors' Contributions}

Rui Kong makes main contribution to this work.

\section{Acknowledgments}

The authors would like to sincerely thank Dr. Jie Lu, Professor Yuejuan Zheng, and Dr. Qi Dai and the staff of the Central Laboratory of Shanghai Tenth People's Hospital for their technical assistance. This study was supported by the National Nature Science Foundation of China (81300340; 81471537).

\section{References}

[1] M. D. Kappelman, S. L. Rifas-Shiman, C. Q. Porter et al., "Direct health care costs of Crohn's disease and ulcerative colitis in US children and adults," Gastroenterology, vol. 135, no. 6, pp. 19071913, 2008.

[2] S. C. Ng, C. N. Bernstein, M. H. Vatn et al., "Geographical variability and environmental risk factors in inflammatory bowel disease," Gut, vol. 62, no. 4, pp. 630-649, 2013.

[3] B. A. Hendrickson, R. Gokhale, and J. H. Cho, "Clinical aspects and pathophysiology of inflammatory bowel disease," Clinical Microbiology Reviews, vol. 15, no. 1, pp. 79-94, 2002.

[4] M. K. Uddin, A. S. Juraimi, M. E. Ali, and M. R. Ismail, "Evaluation of antioxidant properties and mineral composition of purslane (Portulaca oleracea L.) at different growth stages," International Journal of Molecular Sciences, vol. 13, no. 8, pp. 10257-10267, 2012. 
[5] C.-J. Chen, W.-Y. Wang, X.-L. Wang et al., "Anti-hypoxic activity of the ethanol extract from Portulaca oleracea in mice," Journal of Ethnopharmacology, vol. 124, no. 2, pp. 246-250, 2009.

[6] L. F. Hu, X. Y. Xu, and B. Q. Wang, "Research and utilization situation of PortulacaOleracea L. in China," Journal of Pharmacy Practice and Community Medicine, vol. 20, pp. 315-316, 2003.

[7] L. Xiang, D. Xing, W. Wang, R. Wang, Y. Ding, and L. Du, "Alkaloids from Portulaca oleracea L.," Phytochemistry, vol. 66, no. 21, pp. 2595-2601, 2005.

[8] A. N. Rashed, F. U. Afifi, and A. M. Disi, "Simple evaluation of the wound healing activity of a crude extract of Portulaca oleracea L. (growing in Jordan) in Mus musculus JVI-1," Journal of Ethnopharmacology, vol. 88, no. 2-3, pp. 131-136, 2003.

[9] X. J. Zhang, Y. B. Ji, QuZh Y., and et al., "Experimental studies on antibiotic functions of Portulacaoleracea L. in vitro," Chinese Journal of Microbiology and Immunology, vol. 14, pp. 277-280, 2002.

[10] W. Wang, L. Gu, L. Dong, X. Wang, C. Ling, and M. Li, "Protective effect of Portulacaoleracea extracts on hypoxic nerve tissue and its mechanism," Asia Pacific Journal of Clinical Nutrition, pp. 227-233, 2007.

[11] K. Y. Musa, A. Ahmed, G. Ibrahim et al., "Toxicity studies on the methanolic extract of Portulaca oleracea L. (Fam. Portulacaceae)," Journal of Biological Sciences, vol. 7, no. 7, pp. 1293-1295, 2007.

[12] A. T. Reddy, S. P. Lakshmi, and R. C. Reddy, "PPAR $\gamma$ in Bacterial Infections: A Friend or Foe?” PPAR Research, vol. 2016, Article ID 7963540, 2016.

[13] T. D. Hinds, K. John, L. McBeth, C. J. Trabbic, and E. R. Sanchez, "Timcodar (VX-853) Is a Non-FKBP12 Binding Macrolide Derivative That Inhibits PPAR $\gamma$ and Suppresses Adipogenesis," PPAR Research, vol. 2016, Article ID 6218637, 2016.

[14] G. D. Demetri, C. D. Fletcher, E. Mueller et al., "Induction of solid tumor differentiation by the peroxisome proliferatoractivated receptor- $\gamma$ ligand troglitazone in patients with liposarcoma," Proceedings of the National Acadamy of Sciences of the United States of America, vol. 96, no. 7, pp. 3951-3956, 1999.

[15] T. Kubota, K. Koshizuka, E. A. Williamson, and et al., "Ligand for peroxisome proliferator-activated receptor gamma (troglitazone) has potent antitumor effect against human prostate cancer both in vitro and in vivo," Cancer Research, vol. 58, no. 15, pp. 3344-3352, 1998.

[16] S. P. Lakshmi, A. T. Reddy, A. Banno, and R. C. Reddy, "PPAR Agonists for the Prevention and Treatment of Lung Cancer," PPAR Research, vol. 2017, pp. 1-8, 2017.

[17] G. Chinetti, S. Lestavel, V. Bocher, and et al., "PPAR-alpha and PPAR-gamma activators induce cholesterol removal from human macrophage foam cells through stimulation of the ABCA1 pathway," Nature Medicine, vol. 7, no. 1, pp. 53-58, 2001.

[18] L. F. da Rocha Junior, A. T. Dantas, Â. L. B. P. Duarte, M. J. B. de Melo Rego, I. D. R. Pitta, and M. G. D. R. Pitta, "PPAR $\gamma$ agonists in adaptive immunity: what do immune disorders and their models have to tell us?" PPAR Research, vol. 2013, Article ID 519724, 9 pages, 2013.

[19] M. Ricote, A. C. Li, T. M. Willson, C. J. Kelly, and C. K. Glass, "The peroxisome proliferator-activated receptor-gamma is a negative regulator of macrophage activation," Nature, vol. 391, no. 6662, pp. 79-82, 1998.

[20] W. Hozayen, M. Bastawy, and H. Elshafeey, "Effects of Aqueous Purslane (PortulacaOleracea) Extractand Fish Oil on Gentamicin Nephrotoxicity in Albino Rats," Natural Sciences, vol. 9, pp. 47-62, 2011.
[21] A. N. Ananthakrishnan, E. L. McGinley, and D. G. Binion, "Does it matter where you are hospitalized for inflammatory bowel disease? A nationwide analysis of hospital volume," American Journal of Gastroenterology, vol. 103, no. 11, pp. 27892798, 2008.

[22] D. Bojic, Z. Radojicic, M. Nedeljkovic-Protic, M. Al-Ali, D. P. Jewell, and S. P. L. Travis, "Long-term outcome after admission for acute severe ulcerative colitis in Oxford: The 1992-1993 cohort," Inflammatory Bowel Diseases, vol. 15, no. 6, pp. 823828, 2009.

[23] S. Kang, Y. Jeon, K. Moon et al., Journal of Medicinal Food, vol. 20, no. 7, pp. 667-675, 2017.

[24] D. Ristovski-Kornic, A. Stefanović, J. Kotur-Stevuljević et al., "Association of Myeloperoxidase and the Atherogenic Index of Plasma in Children with End-Stage Renal Disease," Journal of Medical Biochemistry, vol. 36, no. 1, pp. 23-31, 2017.

[25] A. Ece, F. Gürkan, M. Kervancioğlu et al., "Oxidative stress, inflammation and early cardiovascular damage in children with chronic renal failure," Pediatric Nephrology, vol. 21, no. 4, pp. 545-552, 2006.

[26] E. Cavusoglu, C. Ruwende, C. Eng et al., "Usefulness of baseline plasma myeloperoxidase levels as an independent predictor of myocardial infarction at two years in patients presenting with acute coronary syndrome," American Journal of Cardiology, vol. 99, no. 10, pp. 1364-1368, 2007.

[27] D. Lau and S. Baldus, "Myeloperoxidase and its contributory role in inflammatory vascular disease," Pharmacology \& Therapeutics, vol. 111, no. 1, pp. 16-26, 2006.

[28] L. Zhang, Y. Zhang, W. Zhong, C. Di, X. Lin, and Z. Xia, "Heme oxygenase-1 ameliorates dextran sulfate sodium-induced acute murine colitis by regulating Th17/Treg cell balance," The Journal of Biological Chemistry, vol. 289, no. 39, pp. 26847-26858, 2014.

[29] D. C. Baumgart and A. U. Dignass, "Intestinal barrier function," Current Opinion in Clinical Nutrition \& Metabolic Care, vol. 5, no. 6, pp. 685-694, 2002.

[30] M. A. Degli-Esposti and M. J. Smyth, "Close encounters of different kinds: dendritic cells and NK cells take centre stage," Nature Reviews Immunology, vol. 5, no. 2, pp. 112-124, 2005.

[31] D. Gómez, N. Muñoz, R. Guerrero, O. Acosta, and C. A. Guerrero, "PPAR $\gamma$ agonists as an anti-inflammatory treatment inhibiting rotavirus infection of small intestinal villi," $P P A R$ Research, vol. 2016, Article ID 4049373, 2016.

[32] H. Baumann and J. Gauldie, “The acute phase response," Trends in Immunology, vol. 15, no. 2, pp. 74-80, 1994.

[33] B. Begue, H. Wajant, J.-C. Bambou et al., "Implication of TNFrelated apoptosis-inducing ligand in inflammatory intestinal epithelial lesions," Gastroenterology, vol. 130, no. 7, pp. 19621974, 2006.

[34] M. N. Ince and D. E. Elliott, "Immunologic and Molecular Mechanisms in Inflammatory Bowel Disease," Surgical Clinics of North America, vol. 87, no. 3, pp. 681-696, 2007.

[35] J. Bauditz, S. Wedel, and H. Lochs, "Thalidomide reduces tumour necrosis factor- $\alpha$ and interleukin 12 production in patients with chronic active Crohn's disease," Gut, vol. 50, no. 2, pp. 196-200, 2002.

[36] S. C. Ng, S. Plamondon, M. A. Kamm et al., "Immunosuppressive effects via human intestinal dendritic cells of probiotic bacteria and steroids in the treatment of acute ulcerative colitis," Inflammatory Bowel Diseases, vol. 16, no. 8, pp. 1286-1298, 2010.

[37] Y. Liu, J. Peng, T. Sun, and et al., "Epithelial EZH2 serves as an epigenetic determinant in experimental colitis by inhibiting 
TNFalpha-mediated inflammation and apoptosis," in Proceedings of the National Academy of Sciences, pp. E3796-E3805, 2017.

[38] R. Ravi, G. C. Bedi, L. W. Engstrom et al., "Regulation of death receptor expression and TRAIL/Apo2L-induced apoptosis by NF- $\kappa$ B," Nature Cell Biology, vol. 3, no. 4, pp. 409-416, 2001.

[39] Y. Chen, H. Ma, D. Zhu et al., "Discovery of Novel Insulin Sensitizers: Promising Approaches and Targets," PPAR Research, vol. 2017, pp. 1-13, 2017.

[40] F. Rosa, J. S. Osorio, E. Trevisi, F. Yanqui-Rivera, C. T. Estill, and M. Bionaz, "2,4-Thiazolidinedione Treatment Improves the Innate Immune Response in Dairy Goats with Induced Subclinical Mastitis," PPAR Research, vol. 2017, pp. 1-22, 2017.

[41] L. Dubuquoy, C. Bourdon, M. Peuchmaur, and et al., "Peroxisome proliferator-activated receptor (PPAR) gamma: a new target for the treatment of inflammatory bowel disease," Gastroenterologie Clinique Et Biologique, vol. 24, no. 8-9, pp. 719724, 2000.

[42] Y. Kawahito, M. Kondo, Y. Tsubouchi et al., "15-deoxy- $\Delta 12,14-$ PGJ2 induces synoviocyte apoptosis and suppresses adjuvantinduced arthritis in rats," The Journal of Clinical Investigation, vol. 106, no. 2, pp. 189-197, 2000.

[43] C. Jiang, A. T. Ting, and B. Seed, "PPAR- $\gamma$ agonists inhibit production of monocyte inflammatory cytokines," Nature, vol. 391, no. 6662, pp. 82-86, 1998.

[44] H. S. P. Souza, C. J. A. Tortori, M. T. L. Castelo-Branco et al., "Apoptosis in the intestinal mucosa of patients with inflammatory bowel disease: evidence of altered expression of FasL and perforin cytotoxic pathways," International Journal of Colorectal Disease, vol. 20, no. 3, pp. 277-286, 2005.

[45] R. Sreedhar, S. Arumugam, V. Karuppagounder et al., "Jumihaidokuto effectively inhibits colon inflammation and apoptosis in mice with acute colitis," International Immunopharmacology, vol. 29, no. 2, pp. 957-963, 2015. 


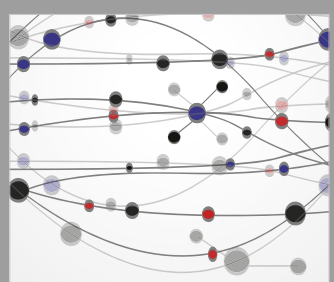

The Scientific World Journal
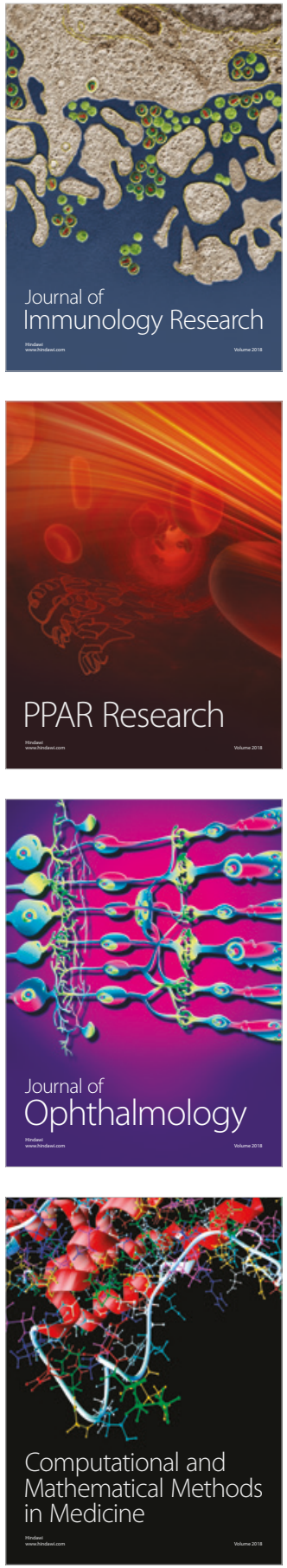

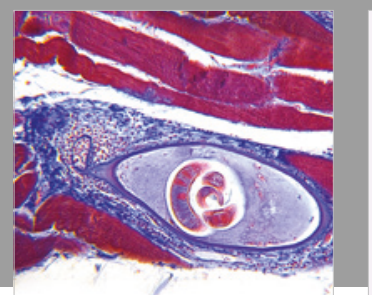

Gastroenterology Research and Practice

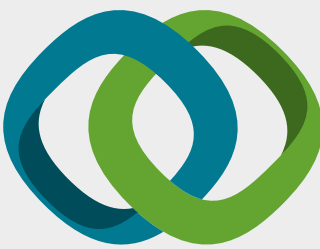

\section{Hindawi}

Submit your manuscripts at

www.hindawi.com
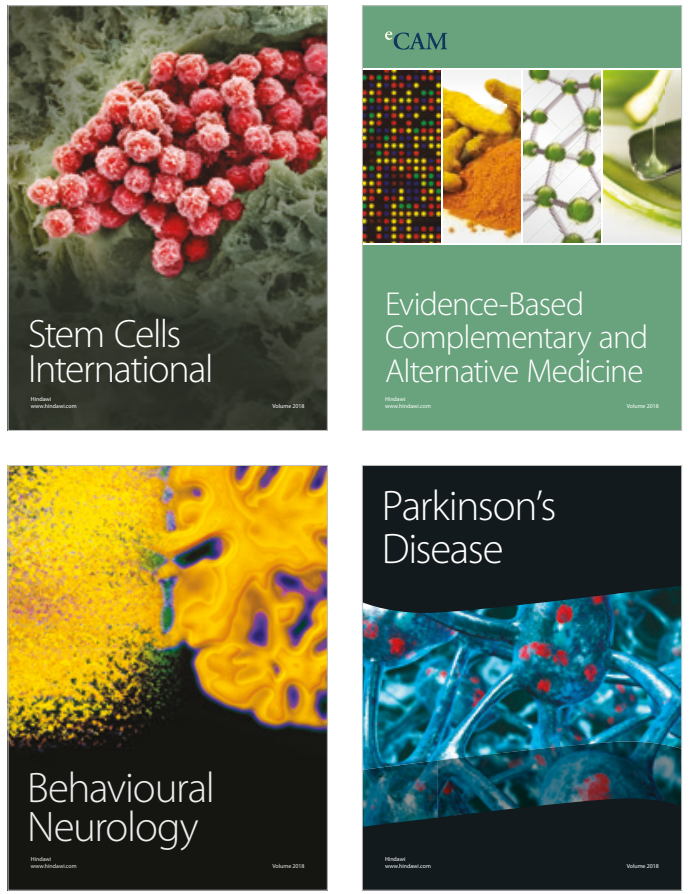

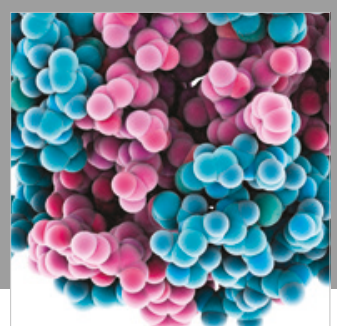

ournal of

Diabetes Research

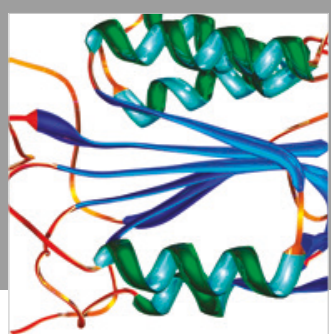

Disease Markers
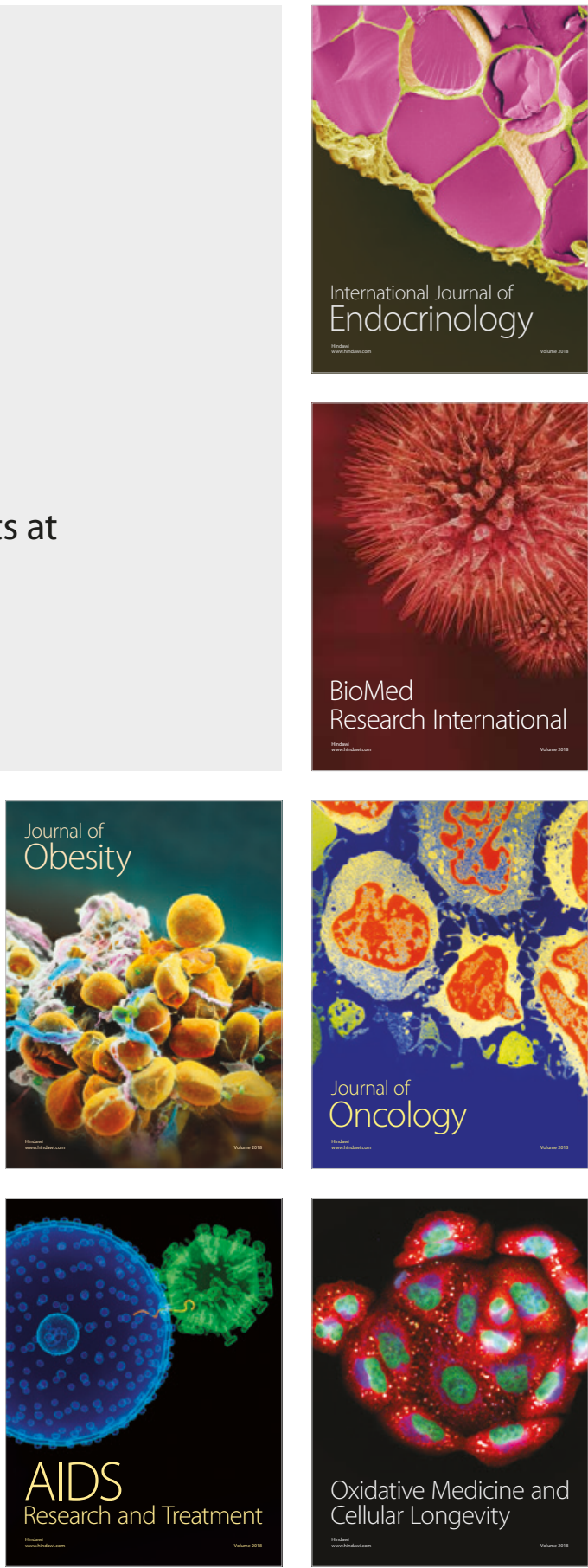